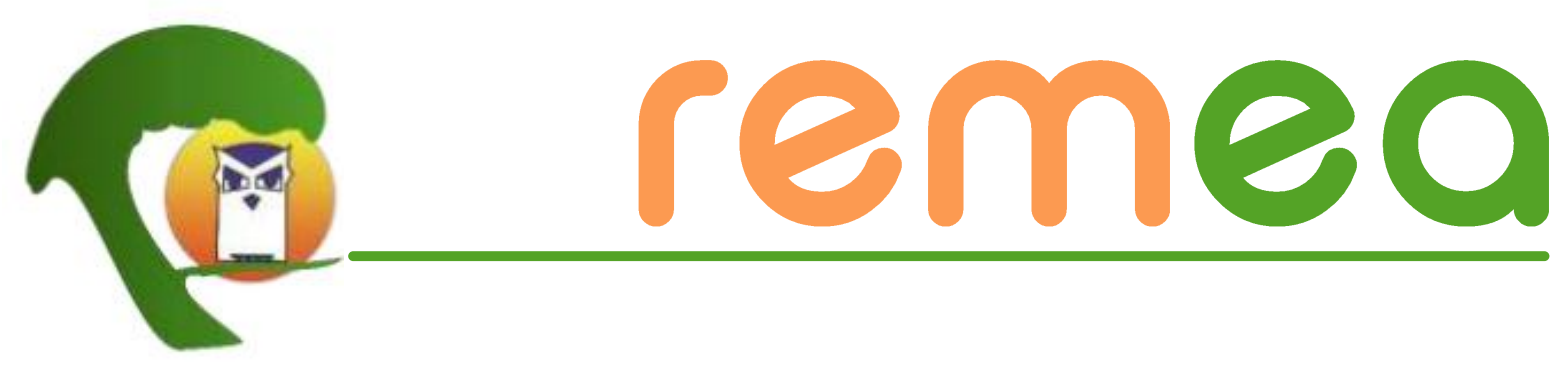

\title{
La (re) generación de la condición humana: la Educación Estético-Ambiental
}

\author{
Pablo René Estévez Rodríguez ${ }^{1}$ \\ Asociación de Pedagogos de Cuba \\ ORCID: https://orcid.org/0000-0003-1654-3563
}

Resumen: El trabajo analiza el impacto anestésico y antiestético de la crisis socioambiental en la condición humana, y el proceso de su regeneración mediante la Educación Estético-Ambiental (EEA). A partir de un esbozo de las causas que han conducido a la desarmonía en la naturaleza humana y no humana, y en consecuencia, a la pérdida de la sustentabilidad estética en el proceso de desarrollo histórico-natural de la especie Homo sapiens, se pondera el papel de la sensibilización estético-ambiental en la preservación y/o rescate de los sentidos "estéticos". Finalmente, se hace un recuento de las experiencias de sensibilización estético-ambiental realizadas con estudiantes, instructores de arte, profesores y miembros de la comunidad, en espacios educacionales de Brasil, Cuba y Chile.

Palabras-clave: Educación Estético-Ambiental; Regeneración estésica y estética; Experiencias de sensibilización.

\section{A (re) generação da condição humana: a Educação Estético-Ambiental}

Resumo: O trabalho analisa o impacto anestésico e antiestético da crise socioambiental na condição humana, e o processo da sua regeneração através da Educação Estético-Ambiental (EEA). A partir do delineamento das causas que têm levado à desarmonia da natureza humana e não humana e, consequentemente, à perda da sustentabilidade estética no processo de desenvolvimento histórico-natural da espécie Homo sapiens, é dada importância ao papel da sensibilização estético-ambiental (SEA) na preservação e/ou resgate dos sentidos "estéticos". Por fim, é feito um relato das experiências de sensibilização estético-ambiental realizadas com alunos, instrutores de arte, professores e membros da comunidade, em espaços educacionais no Brasil, Cuba e Chile.

Palavras-chave: Educação Estético-Ambiental; Regeneração estésica e estética; Experiências de sensibilização.

\footnotetext{
1 Doctor en Ciencias Filosóficas, profesor titular, investigador y escritor. Colaborador del Ministerio de Educación en Cuba y miembro de la Sub-Comisión Nacional de Educación Artística del Instituto Central de Ciencias Pedagógicas. Premio Nacional de Pedagogía 2018. Autor de libros sobre Estética, Filosofía de la Educación y literatura infanto-juvenil. Correo electrónico: esteticaeducacion@gmail.com.
} 
The (re) generation of human condition: the Aesthetic-Environmental Education

\begin{abstract}
The work analyzes the anti-aesthetic and anaesthesical impact of the social-environmental crisis on human condition, and the process of its regeneration through Aesthetic-Environmental Education (AEE). Based on an outline of the causes that have led to disharmony in human and non-human nature, and consequently, to the loss of aesthetic sustainability in the process of natural-historical development of the Homo sapiens species, which reveals the role of aesthetic-environmental sensitization (AES) in the preservation and/or rescue of the "aesthetic" senses. Finally, it alludes to the experiences of aesthetic-environmental sensitization with students, art instructors, teachers and members of the community, in educational spaces in Brazil, Cuba and Chile.
\end{abstract}

Keywords: Aesthetic-Environmental Education; Aesthesical and aesthetic regeneration; Sensitization experiences.

\title{
Introducción
}

Son innumerables las consecuencias de la crisis socioambiental que aqueja al planeta Tierra en los albores del tercer milenio. Muchas tienen que ver con la degradación de los suelos, la pérdida de la biodiversidad, la sobreexplotación de los combustibles fósiles, la disminución de las áreas boscosas, la contaminación de las fuentes acuíferas, la polución ambiental y la desaparición de especies (terrestres y marinas), entre otras. Como colofón, los gases de efecto invernadero como el monóxido de carbono han provocado un cambio climático, que vulnera la sostenibilidad del medio ambiente y ocasiona graves daños a los ecosistemas, con una consecuente reducción del patrimonio estético (natural y social) y un ostensible impacto antiestético en países de todos los continentes.

La crisis tiene como causa fundamental la acción (ecocida) del "Homo sapiens" sobre el entorno circundante en el transcurso de su desarrollo histórico-natural, a partir de la especialización del trabajo y la división de la sociedad en clases con el desarrollo de las fuerzas productivas. Eso creó las condiciones objetivas y subjetivas para el "extrañamiento", según Marx (1965), de nuestros ancestros con respecto al mundo natural y social, para la cosificación y el resquebrajamiento de la condición humana: toda vez que, siendo naturaleza en sí mismo, era de esperar un efecto "dominó" en el proceso de degeneración de la naturaleza (tanto en la porción humanizada como en la salvaje), que habría de degenerar a la especie "pensante y sintiente", y por extensión, el orden social construido a lo largo de su proceso milenario de socialización. La división natural de la incipiente sociedad entre pastores y agricultores y la posterior división de la sociedad en clases, que habría de inducir la emergencia de diversas formaciones económico-sociales (de acuerdo al grado de 
desarrollo de las fuerzas productivas), fueron ocasionando impactos irreversibles de orden físico y social hasta alcanzar los niveles de insostenibilidad que hoy lamentamos.

En particular, la degeneración y (des) armonización de la naturaleza no humana ha llevado a la degradación de la condición humana (en especial, en las dimensiones estésica y estética), que ha incidido en la reducción de las potencialidades genéricas de percepción y creación por las leyes de la belleza en las diferentes esferas de la actividad social. En gran parte, la involución (de la condición humana) es resultado del anestesiamiento y desestetización de los sentidos, que tiene lugar en el proceso de instrumentalización de la naturaleza en la actividad práctico-transformadora por medio del trabajo, lo que condujo al "extrañamiento" entre el hombre y la naturaleza.

Precisamente, el presente trabajo se centra en el impacto anestésico y antiestético de ese "extrañamiento" en la condición humana (en el contexto de la crisis socioambiental contemporánea), y sobre todo, en su regeneración a partir de procedimientos y dinámicas de sensibilización estético-ambiental implementados en espacios educacionales de Cuba, Brasil y Chile.

\section{Desarrollo}

Uno de los problemas más acuciantes de la contemporaneidad lo constituye la crisis socioambiental, cuyas secuelas ponen a la humanidad en una situación de extrema vulnerabilidad. Una de las más graves es la pérdida de la biodiversidad debido, en gran parte, al impacto de la actividad ecocida del Homo sapiens: que ha contaminado el medio ambiente; ha provocado el calentamiento global hasta inducir el cambio climático; ha agotado los combustibles fósiles y ha erosionado las tierras fértiles, poniendo al planeta Tierra al borde de la incompatibilidad con la vida en apenas dos milenios, marcados por la emergencia de amenazas apocalípticas.

\section{Tres grandes amenazas}

De acuerdo a Noam Chomsky y Vijay Prashad, hay tres grandes amenazas a la "Iongevidad de nuestra especie y del planeta" que debemos afrontar en 2021, a saber: a) la 
aniquilación nuclear; b) la catástrofe climática, y c) la destrucción neoliberal del contrato social. Según los autores,

a) Los ya limitados tratados de control de armas están siendo destruidos, mientras las principales potencias poseen cerca de 13.500 armas nucleares (más del $90 \%$ de las cuales están solamente en manos de Rusia y Estados Unidos). El rendimiento de estas armas podría fácilmente hacer este planeta aún más inhabitable. La Armada de Estados Unidos ya desplegó ojivas nucleares tácticas W76-2 de bajo rendimiento [...]

b) En 2018 apareció un artículo científico con un título impactante: "La mayoría de los atolones serán inhabitables a mediados del siglo XXI debido a que el alza del nivel del mar aumentará las inundaciones provocadas por marejadas". Los autores concluyeron que los atolones desde las Seychelles a las islas Marshall están en peligro de desaparecer. Un informe de 2019 de la ONU estimó que un millón de especies animales y plantas están en peligro de extinción. A esto hay que agregar los catastróficos incendios forestales y el grave blanqueamiento de los arrecifes de coral y resulta claro que [...] el peligro no está en el futuro, sino en el presente.

c) Los países de América del Norte y Europa han destripado su función pública a medida que el Estado ha sido entregado a los especuladores y la sociedad civil se ha mercantilizado vía fundaciones privadas. Esto significa que los caminos de la transformación social en estas partes del mundo han sido obstaculizados grotescamente. La terrible desigualdad social es el resultado de la relativa debilidad política de la clase trabajadora. Es esta debilidad la que permite que los multimillonarios establezcan políticas que causan que aumenten las tasas de hambre [...]. El aumento de las tasas de hambre revela que la lucha por sobrevivir es el horizonte para miles de millones de personas en el planeta... (2021)

\section{Luego los autores concluyen que}

La aniquilación nuclear y la extinción por la catástrofe climática son amenazas gemelas para el planeta. Mientras tanto, para las víctimas del ataque neoliberal que ha sido una plaga para la última generación, los problemas de corto plazo para sostener su propia existencia desplazan cuestiones fundamentales sobre el destino de nuestros hijos y nietos. (2021)

El cambio climático, en particular, tiene un enorme impacto antiestético, pues deteriora los valores estéticos inherentes a la naturaleza no humana. Según Iván Smolianinov, "La crisis ecológica tiene un lado espiritual dramático: la crisis estéticoecológica; de la faz de la tierra desaparece con aire amenazador la belleza. El hombre pierde 
su objeto estético, y todos los llamamientos por ahora no han podido detener dicho proceso" (1984, p. 14).

En el informe de 2020 sobre los progresos realizados para lograr los Objetivos de Desarrollo Sostenible (ODS), el Secretario General de las Naciones Unidas reconoció que "La crisis, que está haciendo zozobrar el avance hacia los Objetivos, también está haciendo que su cumplimiento sea aún más urgente y necesario", y añadió al respecto:

Es esencial que [...] se apueste por una recuperación de la COVID-19 de carácter verdaderamente transformador, que reduzca el riesgo de crisis futuras y acelere en gran medida el desarrollo inclusivo y sostenible necesario para cumplir los objetivos de la Agenda 2030 y el Acuerdo de París sobre el cambio climático, primera tarea del decenio de acción. (Naciones Unidas, 2020).

Sin embargo, en el "Resumen anual 2020: El impacto de la COVID-19 (coronavirus) en 12 gráficos", Paul Blake y Divyanshi Wadhwa (2020) advierten sobre las nefastas consecuencias que ha ocasionado la pandemia en los grupos poblacionales más vulnerables, elevando la pobreza extrema hasta niveles insostenibles: lo que obstaculiza una recuperación "de carácter verdaderamente transformador" con un impacto estéticamente significativo respecto a la naturaleza humana y no humana, dentro de los ODS de la Agenda 2030.

Durante los últimos 12 meses, la pandemia ha perjudicado en mayor medida a los pobres y vulnerables, y podría empujar a la pobreza a millones de personas más. Este año, tras décadas de avances constantes en la reducción del número de personas que viven con menos de 1,90 USD al día, la COVID-19 marcará el primer revés en la lucha contra la pobreza extrema en una generación.

En los análisis más recientes se advierte que este año la COVID-19 ha empujado a 88 millones de personas más a la pobreza extrema, y que esa cifra es apenas un punto de partida. En el peor de los casos, podría llegar a 115 millones. El Grupo Banco Mundial (GBM) prevé que el mayor porcentaje de "nuevos pobres" estará viviendo en Asia meridional y que África al sur del Sahara ocupará el segundo puesto, con escasa diferencia. Según la última edición del informe La pobreza y la prosperidad compartida (i), "[e]s probable que [...] muchos de los nuevos pobres trabajen en los servicios informales, en la construcción y en la manufactura, sectores en los que la actividad económica se ve más afectada por los confinamientos y otras restricciones a la movilidad".

No obstante la gravedad que reviste la no satisfacción de las necesidades primarias (para estos millones de personas en pobreza extrema), tal vez la pérdida fundamental se concentre en la esfera de la subjetividad; ya que el deterioro de las condiciones materiales de la existencia humana llevan a una reducción del patrimonio estético (natural y social), y 
por extensión, de las potencialidades de recepción y expresión por las leyes de la belleza inherentes a la especie Homo sapiens.

Nos referimos, en cuestión, a la desestetización del medio ambiente en la medida en que "implosionan" los ecosistemas, en función de la sobrecarga y daños infligidos (en la actividad práctico-transformadora del Homo sapiens) a la naturaleza humanizada y salvaje. Debido a ello, hoy resulta extemporánea la cosmovisión estética de los pitagóricos, que concibieron el universo en términos de una "sinfonía musical universal", y dudosa, la convicción estética schilleriana, según la cual la belleza habría de manifestarse como una condición necesaria de la humanidad. En particular, el empobrecimiento del entorno natural y social conduce al deterioro de los "sentidos estéticos".

\section{El deterioro de los sentidos estéticos}

En virtud de la objetivación del Homo sapiens en el medio natural (en la actividad práctico-transformadora) y, correlativamente, la subjetivación de este (en la actividad cognoscitivo-orientadora), que tienen lugar en la interrelación sujeto-objeto por medio de la praxis, se genera un proceso de desarrollo estésico y estético, en la medida en que los objetos y fenómenos naturales cobran significación estética para el sujeto cognoscente (el Homo sapiens). En razón de lo anterior, según Marx, los sentidos humanos adquieren una nueva calidad y pasan a ser "sentidos estéticos": aptos para la percepción y creación de acuerdo a las leyes de la belleza.

Esos sentidos, precisamente, corresponden al Homo aestheticus; un ente que se asume como naturaleza y que armoniza con el medio en el proceso de objetivación y subjetivación, donde se integran (armoniosamente) la mente racional y la mente emocional, como dos polos inseparables de su carácter bipolar. Todavía no ha tenido lugar el proceso de "extrañamiento", que vulnera los nexos del Homo sapiens con el entorno natural y que conduce, finalmente, a la pérdida de la potencialidad estético-ambiental de la especie y a la degeneración estésica y estética de la condición humana. Este proceso se desencadena cuando la incipiente organización de la sociedad va complejizándose: al principio, por la división natural del trabajo en la antigua gens, y luego, por la división de la sociedad en clases antagónicas, dando origen al surgimiento de las formaciones económico-sociales 
(como el esclavismo, el feudalismo y el capitalismo), que acrecentaron los niveles de enajenación del Homo sapiens respecto a la naturaleza circundante y, con ello, el deterioro de los sentidos estéticos y de la sustentabilidad de la propia condición humana, un proceso que se agudizó con la instrumentalización de la razón en la Modernidad.

\section{La racionalidad instrumental}

La degeneración de los sentidos tiene lugar en un juego de lanzadera entre la mente racional y la mente emocional, a medida que la Modernidad va instaurando una cosmovisión racionalista que, basada en el auge de la ideología cientificista (potenciada por los adelantos científico-técnicos), subvierte la percepción estética del universo instaurada por los pitagóricos en base a la legalidad (estética) que intuían en los objetos y fenómenos naturales.

La instrumentalización de la razón, que Horkheimer denominó “enfermedad de la razón" (1973), condujo a la subvaloración de la subjetividad y, por consiguiente, a la desvalorización social de las emociones, de los sentimientos y de la sensibilidad como elementos determinantes en la actividad cognoscitivo-orientadora de la personalidad (concebida como una totalidad). Según Humberto Maturana (1991, p. 88),

Vivimos una cultura que ha desvalorizado a las emociones en función de una supervaloración de la razón, en un deseo de decir que nosotros, los humanos, nos diferenciamos de los otros animales en que somos seres racionales. Pero resulta que somos mamíferos, y como tales, somos animales que viven en la emoción.

Jóvenes investigadores, como Lurima Estevez, han insistido en el impacto nihilista de la desvalorización de las emociones en la condición humana. Según ella, la "cura" de la enfermedad de la razón "[...] reclama la presencia de las emociones y una terapia radical en términos de repoblación axiológica de la conciencia, en aras del rescate de la condición humana, cuya sustentabilidad estética se torna cada vez más vulnerable" (2019, p. 49). Precisamente, en función del rescate emocional de los educadores, Lurima ha desarrollado técnicas y dinámicas de sensibilización estético-ambiental y las ha implementado con miembros de comunidades, instructores de arte, estudiantes, promotores de la cultura y profesores en espacios docente-educativos de Cuba, Brasil y Chile: con resultados relevantes 
en un contexto hostil de la vida contemporánea, donde aparecen nuevas amenazas a la condición humana (2019, p. 121-158). ${ }^{2}$

\section{Nuevas amenazas a la naturaleza humana}

En el estadio crítico de la sociedad contemporánea, caracterizado por la irracionalidad y virulencia de sus contradicciones, han emergido nuevas modalidades del control social, vinculadas a las tecnologías de punta surgidas al calor de la cuarta revolución científico-técnica. Nos referimos, en síntesis, al Big Data; a la inteligencia artificial y a la nanotecnología, y asociadas a ellas, a la "posverdad", la face new y la "infodemia". Todas ellas son destinadas a la construcción de una realidad virtual como hipóstasis de la realidad objetiva, que resulta incómoda a las transnacionales detentoras del poder real y a las élites gobernantes, en función de cuyos intereses trabaja un ejército de intelectuales orgánicos: científicos, economistas, politólogos, sociólogos, psicólogos, periodistas y otros, que crean una falsa conciencia y desubstancian la condición humana.

Es obvio que en esas condiciones resulta difícil orientarse en el complejo mundo de los valores, en lo que veía Antonio Gramsci (1973) el sentido de la educación. Con el desarrollo de las tecnologías de las comunicaciones, la información y la internet, hoy es posible almacenar y procesar datos acerca del comportamiento poblacional, según Raúl A. Capote $(2020$, p. 1), para "predecir atributos ocultos, entre ellos, preferencias políticas, orientación sexual, cuánto confía usted en las personas con las que se relaciona, cuán sólidas son esas relaciones, todo gracias a la información que los propios usuarios suben a las redes". Debido al cúmulo de informaciones falsas (las face news); a las distorsiones de la verdad, que han dado lugar a la emergencia de la "posverdad" (como sucedáneo virtual de la verdad objetiva), y a la subversión ideológica orientada a desestructurar al Homo sapiens como ente sintiente, pensante e independiente (con capacidad de autorregulación), el peligro de cosificación y enajenación del Homo sapiens es más real que nunca antes en el proceso de su hominización. Todo en aras de convertirlo en una especie de robot, de consumidor pasivo y obediente: orgánico a la lógica del capital.

\footnotetext{
${ }^{2}$ El autor participó en la organización y realización de las experiencias de Cuba.
} 
En lo que respecta al desarrollo estésico y estético (tributarios de los sentidos estéticos y, correlativamente, de la cultura de los sentimientos y de la sensibilidad), asistimos hoy a la globalización de la fealdad y al anestesiamiento global, en función de lo cual se desdibujan los límites de lo estético, lo artístico y lo kitsch, dando lugar a una confusión epistemológica que desemboca en el nihilismo, la banalidad y lo grotesco. Algunas de esas manifestaciones (seudoartísticas), vinculadas a la "ecología verde", el marketing (anti) estético y a la propaganda comercial de las grandes transnacionales que contaminan el medio ambiente, han dado lugar a la Estética Burguesa Estandarizada, según la denominara Wagner Valente dos Passos (2018) en un acucioso estudio sobre el "marketing estético" de algunos emporios industriales de Brasil, donde revela el "fetichismo, la alienación y la ideología capitalista" subyacentes.

Si a lo anterior se suma el dominio cuasi absoluto que las redes sociales ejercen sobre la subjetividad humana (Facebook, Instagram y Whatsapp, entre otras), así como el crecimiento exponencial de la velocidad en las conexiones con el desarrollo de las tecnologías 4G y 5 G y la invasión de los celulares "inteligentes", se comprende la aprensión de los educadores por la formación (integral) de la personalidad: toda vez que en esas condiciones queda poco espacio para el desarrollo de una conciencia crítico-transformadora, que requiere tiempo y espacio para el distanciamiento estético (necesario para la ponderación de los valores estético-artísticos, y sobre todo, para el cultivo del gusto, el ideal y las convicciones estéticas inherentes a una personalidad estéticamente desarrollada). En lugar de ello, proliferan el mal gusto, el kitsch, la banalidad y la chabacanería, que inhiben la capacidad de aprehensión y creación por las leyes de la belleza: una capacidad de la que hacían gala nuestros ancestros, según puede constatarse en los palimpsestos de las cavernas de Altamira y Lascaux, entre otras expresiones del "arte rupestre"; aún cuando esas expresiones tenían una función mágico-religiosa y el arte estaba lejos de ser considerado una forma específica de la conciencia social.

La pérdida de las cualidades estéticas de los objetos y fenómenos naturales; el extrañamiento respecto al entorno natural y social y, como consecuencia, la incapacidad para establecer relaciones empáticas con la Otredad (sujetos, otras especies de la biodiversidad, y objetos en general), han menoscabado las capacidades estésica y estética de 
los seres humanos, y por extensión, la condición estética de la naturaleza humana. Dicho de otra manera: la naturaleza estética del Homo sapiens ha dejado de ser sustentable en la medida en que ha dejado de ser sustentable la naturaleza no humana y se han ido deteriorando los sentidos estéticos. Ante ello, la sustentabilidad estética como principio del desarrollo humano y social adquiere una extraordinaria relevancia.

\title{
La sustentabilidad estética
}

En A alternativa estética na educação (2009, p. 60-61), se define la sustentabilidad estética con un carácter instrumental:

\begin{abstract}
[Se denomina] sustentabilidad estética a la escala o espectro valorativo que se corresponde, en términos generales, con el ideal social de perfección genérica (indicador de la cualidad estética) de los objetos y fenómenos de la realidad objetiva. Por ese motivo., debe ser asumida como medida de la dimensión cualitativa del desarrollo económico y social, y humano en general, con el objetivo de evaluar el impacto (positivo o negativo) sobre los objetos y fenómenos que, desde el punto de vista estético, son afectados por él y que afectan al propio hombre, ya que la degradación de las condiciones estéticas del medio ambiente corroe la conciencia estética (individual y social), empobrece la actividad orientadora valorativa, y específicamente estética, del individuo en el mundo circundante.
\end{abstract}

Por la pertinencia de dicho concepto para preservar la condición estética de la naturaleza humana y no humana, debiera asumirse como un principio del desarrollo humano y social, a la vez que como un principio de la Sociología Ambiental, en razón de lo cual constituye uno de los conceptos centrales de la Educación Estético-Ambiental. Eso presupone un cambio de la mentalidad racionalista que perdura en la cultura occidental y que es aupada por instituciones prestigiosas en el seno de la comunidad internacional. Podríamos poner como ejemplo el concepto de "Desarrollo" que promueve el PNUD basado en un grupo de aspectos considerados esenciales como: la potenciación, la cooperación, la equidad, la sustentabilidad y la seguridad, pero donde no se explicitan indicadores que tributen al desarrollo de la subjetividad humana, y en particular, a los sustratos estésico y estético sobre los cuales se sustenta. En A Educação Ambiental em perspectiva estética (2011, p. 31), se afirma al respecto:

La omisión del factor estético se hace ostensible también en el IDH (Índice de Desarrollo Humano [...] aún cuando este pretende constituir "una medida general,

Revista Eletrônica do Mestrado em Educação Ambiental 
sintética, del desarrollo humano". En general, se trata de un concepto con una orientación pragmático-utilitarista que trata de medir el desarrollo humano en términos cuantitativos, soslayando aspectos fundamentales como el nivel de la conciencia estética alcanzado por una comunidad.

Las Naciones Unidas serían más consecuentes con la comunidad internacional, si el PNUD considerara también el impacto negativo sobre la condición humana de índices que, supuestamente, la sustentan: como el Producto Interno Bruto (PIB). Es decir, si hiciera una lectura inversa, complementaria, del IDH: donde la letra " $\mathrm{D}$ " designara también la degeneración de la condición humana en función del impacto que genera el propio "desarrollo".

En este sentido, como era de esperar en un enfoque racionalista y utilitarista del desarrollo humano y social, las Metas para el Desarrollo Sostenible de la Agenda 2030 se quedan por debajo de las expectativas (de orden estésico y estético) que esbozamos aquí: toda vez que se anteponen aspectos de orden material con la finalidad de satisfacer necesidades primarias, relacionadas con la alimentación y la protección del medio ambiente. A ese enfoque reductor del PNUD, se opone la Educación Estético-Ambiental a partir de una perspectiva holística, que justiprecia los aspectos sensibles y humanos de todo desarrollo (humanamente) sostenible.

\section{La Educación Estético-Ambiental}

A partir de las investigaciones $y$, sobre todo, de la praxis docente-educativa del Centro Latinoamericano de Educación Estética y Ambiental (CELEA) "La Edad de Oro" (auspiciado por la Universidad Central "Marta Abreu" de Las Villas y el Instituto Superior Pedagógico "Félix Varela" de Villa Clara, desde 1993), emergió una nueva modalidad de la educación en valores con una orientación transversal, transartística y transdisciplinar de lo estético y de lo ambiental: la Educación Estético-Ambiental (EEA), urgida en especial por las demandas de carácter estético y ambiental de las escuelas de las enseñanzas primaria y secundaria de la provincia Villa Clara (Cuba).

Constituyeron hitos fundamentales en el desarrollo de la EEA, la creación de las Cátedras de Educación Estética y Ambiental (CEEAs) en las escuelas de las diferentes enseñanzas; la organización de dos encuentro-talleres internacionales de Educación Estética 
y Ambiental (Instituto Superior Pedagógico "Félix Varela", 1993 y 1995), y posteriormente, las actividades docente-investigativas y extensionistas desarrolladas durante ocho años en la Universidade Federal do Rio Grande-FURG entre 1999 y 2003, y en una segunda etapa, entre 2008 y 2012: especialmente, en el Programa de Posgrado en Educación Ambiental (PPGEA), donde fueron creados el Núcleo de Pesquisa, Estudio y Extensión en Educación Estética (NUPEE), en el año 2002, y el Proyecto Transcultural de Educación Estético-Ambiental (EcoEstética), adscripto al CNPq, en el año 2008. A este respecto, tuvo una gran relevancia la impartición de la disciplina optativa "Educación Estético-Ambiental" en el PPGEA durante ocho semestres, pues los intercambios que propició con alumnos y profesores facilitaron la socialización de sus fundamentos teórico-metodológicos, a la vez que constituyó una importante fuente para la publicación de artículos y libros, así como para la realización de trabajos de maestría y tesis de doctorado. ${ }^{3}$

Un aspecto importante en la sistematización de la EEA lo constituyó la extensión de las prácticas docente-investigativas a otras instituciones educacionales de Rio Grande y a otras regiones de Brasil, como la Universidade Federal do Pampa (Unipampa), la Universidade Federal de Pelotas (UFPel), la Universidade Federal de Santa Catarina (UFSC) y la Universidade Federal de Curitiba (UFC), entre las más sobresalientes. Por otra parte, se han desarrollado estudios e impartido talleres de sensibilización estético-ambiental en espacios educacionales de Chile, donde llegó a crearse una Agencia Latinoamericana para el Desarrollo de la Educación Ambiental centrada en la promoción de la Educación EstéticoAmbiental. ${ }^{4}$

En lo que respecta a Cuba, además de la labor teórico-metodológica y práctica del CELEA, ha tenido lugar la publicación de artículos en revistas de impacto (dentro y fuera del país), empezando por las revistas REMEA y Ambiente \& Educação, de la maestría y el doctorado del PPGEA, respectivamente, así como la publicación de libros sobre sus

\footnotetext{
${ }^{3}$ Muchos de los trabajos generados por los debates y reflexiones en torno a la Educación Estético-Ambiental fueron compilados en la antología: A Educação Ambiental em perspectiva estética (Editora da FURG, 2011). Recientemente, la tesis de doctorado de Lurima Estevez Alvarez publicada por la Editorial Universitaria Félix Varela, de Cuba, fue galardonada con el Premio Anual de Investigación Cultural que otorgan el Instituto Nacional de Investigaciones Culturales "Juan Marinello", de La Habana, y el Ministerio de Cultura.

${ }^{4}$ La Agencia Latinoamericana para el Desarrollo de la Educación Ambiental (ALDEA, Chile), fue creada y presidida por Lurima Estevez a partir de sus vínculos con el Proyecto "Educar para el Bien y la Belleza", de la Filial de la Asociación de Pedagogos de Cuba en Villa Clara, y de sus estudios doctorales en el PPGEA.
}

Revista Eletrônica do Mestrado em Educação Ambiental 
fundamentos y temáticas afines (tanto en Cuba como en Brasil). Por otra parte, se diseñó el Programa "Teoría y práctica de la Educación Estética” para la Licenciatura en Educación Artística de las universidades cubanas y una adecuación para las escuelas de formación de maestros, sobre la base de los fundamentos teóricos y metodológicos de la Educación Estético-Ambiental.

Además de lo anterior, a solicitud de las filiales de la Asociación de Pedagogos de Cuba (APC) en las provincias de Cienfuegos y Villa Clara, se implementa el Proyecto "Educar para el Bien y la Belleza" en el preescolar, la escuela primaria y la secundaria básica, con procedimientos pedagógicos específicos para la educación estético-ambiental: como la "Pedagogía del niño lindo", la "Pedagogía de la medida y el cuidado" y la "Ambientación estética de la escuela", orientados a la formación integral de escolares y estudiantes desde una perspectiva estético-ambiental (transdisciplinar): lo cual sirve de fundamento teórico y metodológico para el diseño de técnicas y dinámicas de sensibilización estético-ambiental, implementadas en las escuelas mediante los talleres respectivos.

\section{Experiencias de sensibilización estético-ambiental}

Como parte de sus actividades docente-educativas e investigativas, Lurima $^{5}$ ha desarrollado experiencias de sensibilización estético-ambiental con alumnos de la Licenciatura en Artes Visuales, de la FURG; con instructores de arte, promotores de la cultura y profesores de la ciudad de Manicaragua, en Cuba, y educadores y miembros de las comunas en El Maule, Chile, donde ha obtenido resultados relevantes (según consta en las narrativas y en las evaluaciones de los talleres realizados), lo cual evidencia la pertinencia social de la EEA como modalidad de la educación valórica, en una etapa compleja del desarrollo histórico-natural del Homo sapiens: algo que podemos colegir por las siguientes inferencias (2019, p. 174-175):

a) Las categorías Educación Estético-Ambiental y Formación más Integral (la primera en función del desarrollo de la segunda), cohesionadas en los enunciados: "La EEA y su papel para una formación más integral de los (as) educadores (as) en Arte: representaciones de los (as) académicos (as) em Artes Visuais - Licenciatura

\footnotetext{
${ }^{5}$ Lurima es gestora y colaboradora del Proyecto "Educar para el Bien y la Belleza", a cuyas proyecciones responden sus técnicas y dinámicas de sensibilización estético-ambiental desarrolladas, especialmente, en la provincia de Villa Clara (Cuba).
} 
de la FURG" y "La EEA y su papel para una formación más integral de los (as) educadores (as) en Arte: representaciones de los (as) instructores (as) de Arte de Manicaragua", permitieron comprender las representaciones de los sujetos colaboradores en torno a la importancia y trascendencia para el desarrollo de procesos educativo-pedagógicos enfocados en la formación de valores y en la convivencia estética del hombre en el medio natural y social.

b) El papel relevante de la EEA para una formación más integral de educadores (as) en arte, ya que su perfil profesional tiene una proyección holística (que engloba la tríada enseñanza, investigación y extensión) y una orientación humanista que es consustancial, por naturaleza, a toda modalidad de la educación en valores.

d) La pertinencia del enfoque transdisciplinar y transartístico en el proceso docente-educativo, que permite ejercer un impacto integrador y compensatorio sobre la conciencia humana en armonía con su carácter integral y unitario; racional y emocional (en función de una formación más armoniosa e integral).

e) La necesidad de la ambientación curricular de los cursos de formación de educadores, especialmente de arte.

\section{Estas inferencias tienen su correlativo en trechos de las narrativas que se obtuvieron}

después de realizados los talleres, en especial, con la muestra de Manicaragua (2019, p.128131):

a) El ejercicio fue algo novedoso para mí, despertó ideas para practicar en el ejercicio pastoral. (I-1)

b) El ejercicio de sensibilización fue muy especial para mí porque logré experimentar con mi cuerpo cada sugerencia que dio la profesora. Sentí que mis brazos pesaban y se alargaban, que no podía mover los pies, que la cabeza se hacía más grande, en fin, olvidé mi realidad y fui por unos minutos, un árbol, que echaba raíces y refrescaba el entorno. Mi objeto fue un tubo de pegolín y me recordó a mi hija mayor, tiene 6 años y está en $1^{\text {er }}$ grado, ella adora romper los libros, y luego pegar las imágenes como si contara su propia historia [...] ha roto incluso documentos importantes y por ello la he castigado e incluso pegado y al oler el objeto sentí nostalgia y me dije a mí misma no lo hagas más, la vida es muy corta y ella es lo mejor que nos ha pasado a mi esposo y a mí. Es increíble, un ejercicio como este te hace recordar que eres un ser humano y debes actuar como tal. (I-2)

c) Le diré que tengo una experiencia nueva referente a la vida que por medio de la concentración la persona puede "sentir sensaciones", olores, pensamientos, sueños, etc. (I-4)

d) La significación del ejercicio [fue] excelente ya que hizo reactivar todos mis "procesos cognitivos", "afectivos" [y] realizarme espiritualmente principalmente "sentir la energía" propia de sí mismo [...]. (I-5)

e) El ejercicio significó para mí [...] que hay que "apreciar las cosas" en la vida y darle un "valor". (I-7)

f) Durante el ejercicio me sentí [...] feliz al conectarme con mi cuerpo y sentimientos, pues a veces en la vida no lo hago, estoy tan ocupado que vivo para mí. [...] mi objeto me recordó aquellos recuerdos lejanos y me di cuenta que el tiempo ha pasado y me dormí. ¡Es tiempo de decir te quiero, "lo siento", me

Revista Eletrônica do Mestrado em Educação Ambiental 
encanta mi familia, quiero una vida! No me acomodaré más pues el tiempo pasa aunque no me haya dado cuenta. iGracias por "despertarme"! (I-8)

g) [...] fue un momento de total relajación, "espiritualidad" y "reflexión" [...]. Me hizo pensar en los pequeños detalles que engrandecen el alma y me enorgullecen... Estoy muy agradecida por haber vivido un momento tan especial. (I-9)

h) Este ejercicio significó un "pare" en mi actividad cotidiana para "meditar", asociar y encauzar la "sensibilidad estética" ambiental. (I-13)

i) Fue divino [...]. Creo que todo en la vida lo tengo que hacer rápido porque las horas pasan, el tiempo es corto pero descubrí y también aprendí que debemos darnos una oportunidad para recordar, "pensar", porque es volver a vivir. [...] Gracias porque lo necesitaba y mi mundo, mi "sueño" que es el teatro lo viví, lo sentí cerca porque son ejercicios que te ayudan con el mal carácter, el miedo, la soledad y los problemas que tenemos. Soy "feliz" (hoy). (I-14)

j) [...] logré "sentirme" muy relajada, creé un ambiente interno que hizo que recordara momentos, lugares, objetos, personas de gran importancia en mi vida y sentí satisfacción, regocijo; "plenitud" al lograr establecer esta conexión con solo palpar y oler un objeto desconocido. (I-15)

k) "[...] tocó una parte muy "sensible" de mi persona. Me trajo "lindos recuerdos" de cuando era niña, además de "sentirme" en un ambiente seguro [...] sirvió para liberar el estrés diario. (I-16)

I) El ejercicio para mí tuvo una significación muy grande [...]. Realmente al comienzo [...] estaba muy estresada y contraída por diferentes problemas que en estos tiempos me perturban pero al terminar el ejercicio me "sentí libre", me sentí relajada; en verdad "me sentí muy bien". Fue asombroso porque nunca había tenido una experiencia así. (I-18)

m) [...] como persona me "senti" totalmente "sensible" a todas las cosas que están pasando actualmente en nuestra sociedad. Como los "valores" y los "sentimientos" humanos se están degradando cada día más. (I-19)

n) [...] En mi vida personal mientras hacía este ejercicio me remitió a mi niñez y tuve tantos "recuerdos tan lindos" que me hizo "comprender" cosas en las cuales estoy actualmente equivocado a la hora de criar a mis dos pequeñas y trabajaré para cambiar mis métodos. Muchas gracias por esta oportunidad de aprender. (I20)

ñ) [...] significó un viaje a la "sensibilidad" del ser humano [...] logré sustituir el objeto por la foto en que mi mamá me sostiene entre sus brazos. (I-21)

En consonancia con lo anterior, en la evaluación del aspecto "Caracterización y percepción del nivel de importancia de los talleres" los participantes en la mencionada muestra (25 sujetos ${ }^{6}$ ), dejaron constancia de la elevada valoración de las experiencias en

\footnotetext{
${ }^{6}$ Los sujetos integrantes de la muestra son identificados con la letra "I".
} 
función de "su contenido humanista, excelencia académica, dinamismo, coherencia, creatividad y novedad desplegados por la profesora en su implementación". (2019, p. 147).

Estos resultados son convincentes y demuestran la pertinencia de las técnicas y dinámicas de sensibilización estético-ambiental, dirigidas a recuperar las capacidades estésica y estética de la personalidad en el contexto de la sociedad contemporánea, donde imperan la racionalidad instrumental, la banalidad y la fealdad: orgánicas a la naturaleza del capitalismo transnacional.

Es hora de rectificar la lógica de las políticas desarrollistas para que el desenvolvimiento (humano y social) sea, realmente, sostenible. En lo que respecta a la naturaleza humana, la sostenibilidad ha de incorporar el cultivo de la mente emocional: en un enfoque integral (unitario) de la personalidad, que incluye a la mente racional. Todo ello en aras del despliegue de las potencialidades del Homo sapiens, y en primer lugar, de las de carácter estésico y estético que, en última instancia, determinan su condición humana. De no hacerlo, no se encontrará una alternativa viable al proceso de deshumanización que sufre nuestra especie, y la sociedad en su conjunto, en el transcurso del tercer milenio de la "civilización".

\section{Consideraciones finales}

Ante las urgencias de la crisis socioambiental, y en particular, ante el impacto anestésico y antiestético del cambio climático en la naturaleza humana, es necesario cambiar la forma (racionalista) de pensar el mundo y las relaciones intersubjetivas, privilegiando el saber sensible, la empatía y la armonía como reguladores del orden social, en aras de un desarrollo (humano y social) verdaderamente sostenibles, y en primer lugar, de la sustentabilidad estética de la propia naturaleza humana.

Urge, asimismo, implementar técnicas y dinámicas de sensibilización orientadas a una formación más integral de la personalidad, y en especial, al desarrollo de una cultura de los sentimientos y de la sensibilidad estético-ambiental, como complemento de las transformaciones socioeconómicas y políticas encaminadas al cumplimiento de los ODS de la Agenda 2030. 
En función de lo anterior, debe repensarse la educación desde una perspectiva holística, que contemple la interrelación dialéctica entre la mente racional y la mente emocional. Precisamente, a ese objetivo, sirve la Educación Estético-Ambiental como modalidad de la educación en valores basada en la universalidad y unidad de los valores estéticos y ambientales, asumidos en una perspectiva transdisciplinar. Por lo tanto, su sistematización en la praxis docente-educativa, resulta una condición sine qua non para la preservación y/o regeneración de la condición humana en el contexto (estéticamente insostenible) de la sociedad contemporánea.

\section{Referencias}

BLAKE, Paul; WADHWA, Divyanshi. Resumen anual 2020: El impacto de la COVID-19 en 12 gráficos. 2020. Disponible en: https://blogs.worldbank.org/es/voices/resumen-anual-2020el-impacto-de-la-covid-19-coronavirus-en-12-graficos. Acceso: 30 ene. 2020.

CAPOTE, Raúl Antonio. El Big Data y la ciencia de la manipulación de las masas. Granma, La Habana, N. 217, Año 56, p. 1, 10 sept. 2020.

CHOMSKY, Noam; PRASHAD, Vijay. Tres grandes amenazas a la vida en la Tierra que debemos afrontar en 2021. Instituto Tricontinental de Investigación Social y ALAI, 8 ene. 2021.

ESTEVEZ, Lurima. La Educación Estético-Ambiental. La Habana: Editorial Universitaria Félix Varela, 2019.

ESTÉVEZ, Pablo René. A alternativa estética na educação. Rio Grande: Editora da FURG, 2009.

ESTÉVEZ, Pablo René. La sustentabilidad estética en el Desarrollo Humano. En: ESTÉVEZ, Pablo René (org.). A Educacao Ambiental em perspectiva estética. Rio Grande: Editora da FURG, 2011.

GRAMSCI, Antonio. Socialismo y cultura. La Habana: Editorial de Ciencias Sociales, 1973.

HORKHEIMER, Max. Crítica de la Razón Instrumental. Buenos Aires: El Ateneo, 1973.

MARX, Carlos. Manuscritos económicos y filosóficos de 1844. La Habana: Editora Política, 1965.

MATURANA, Humberto. Emociones y lenguaje en Educación y Política. 4. ed. Santiago de Chile: CED (Centro de Estudio de Desarrollo), Colección Hachette-Comunicación, 1991. 
Progresos realizados para lograr los Objetivos de Desarrollo Sostenible. Informe del Secretario General de las Naciones Unidas. Período de sesiones de 2020 ( 25 de julio de 2019 a 22 de julio de 2020. Temas 5 (a) y 6 del programa), 2020.

SMOLIANINOV, Iván. La naturaleza en el sistema de la Educación Estética. Moscú: Ed. Prosvieshenie, 1984.

VALENTE DOS PASSOS, Wagner. Revolução Estética e Educação Ambiental: uma proposta de oposição ao fetichismo, à alienação e à ideologia capitalista. 192 p. Tese (Doctorado en Educación Ambiental). Universidade Federal do Rio Grande-FURG, Rio Grande. 2018. Disponible en: https://sistemas.furg.br/sistemas/sab/arquivos/bdtd/0000012533/. Acceso: 6 feb. 2021.

Submetido em: 08-02-2021.

Publicado em: 23-04-2021. 